\title{
YEAR-AROUND C- AND L- BAND OBSERVATION AROUND THE MOSAIC ICE FLOE WITH HIGH SPATIAL AND TEMPORAL RESOLUTION
}

\author{
Suman Singha*1, Malin Johansson ${ }^{2}$, Gunnar Spreen ${ }^{3}$, Stephen Howell ${ }^{4}$, Shin-ichi Sobue ${ }^{5}$, Malcolm Davidson $^{6}$ \\ ${ }^{1}$ German Aerospace Center (DLR), Bremen, Germany \\ ${ }^{2}$ UiT The Arctic University of Norway, Troms $\varnothing$, Norway \\ ${ }^{3}$ University of Bremen, Bremen, Germany \\ ${ }^{4}$ Environment and Climate Change Canada (ECCC), Canada \\ ${ }^{5}$ Japan Aerospace Exploration Agency (JAXA), Japan \\ ${ }^{6}$ European Space Agency (ESA), Netherland
}

\begin{abstract}
In September 2019, the German research icebreaker Polarstern started the largest multidisciplinary Arctic expedition, the MOSAiC (Multidisciplinary drifting Observatory for the Study of Arctic Climate) drift experiment. Being moored to ice floes at high Arctic for a whole year, thus including the winter season, the main goal of the expedition is to better understand and quantify relevant processes within the atmosphere-ice-ocean system that impact the sea ice, ultimately leading to improved climate models. Satellite remote sensing, specially multi-frequency synthetic aperture radar (SAR) plays a major role to achieve this goal. Two major objectives in SAR based remote sensing of sea ice is on the one hand to have a large coverage, and on the other hand to obtain a radar response that carries as much information as possible. A comprehensive set of C- and L- band SAR images were acquired during the course of MOSAiC. In this initial study we evaluate the effects of seasonal changes on C- and L-band backscatter in respect to three different sea ice types, i.e., Young Ice, Smooth Ice and Rough/Deformed Ice along with the performance of sea ice type retrieval of a established algorithm. Areas of deformed, smooth and young sea ice were observed in the vicinity of R/V Polarstern and these areas are included whenever possible in the yearlong time series. For both frequencies a change in all backscatter
\end{abstract}

\footnotetext{
*Corresponding Author E-mail: Suman.Singha@dlr.de. Data used in this manuscript was produced as part of the international Multidisciplinary drifting Observatory for the Study of the Arctic Climate (MOSAiC) with the tag MOSAiC20192020. The research is funded through DFG (MOSAiCmicrowaveRS), EMS-III, CIRFA (grant number 237906), OIBSAR (grant number 280616) and SIDRiFT (grant number 287871). ALOS-2 PALSAR-2 scenes were acquired under the agreement between ESA and JAXA on the cooperation for the use of synthetic aperture radar satellites in earth science and applications and obtained via 2nd Earth Observation Research Announcement Collaborative Research Agreement (PI: Suman Singha and Torbjørn Eltoft). RADARSAT-2 acquisitions were coordinated by Polar Space Task Group (PSTG), additional RADARSAT-2 acquired via NSC/KSAT under the Norwegian-Canadian Radarsat agreement 2019 and 2020 and through DLR collaborative ground segment and ESA TPM.
}

channels values can be observed during the early melt season. This is first noticeable in the C-band images and later followed by a change in the L-band images, probably caused by their different penetration depth and volume scattering sensitivities.

Index Terms - MOSAiC; Sea Ice Type; Polarimetry; SAR; ALOS-2 PALSAR-2; RADARSAT-2.

\section{INTRODUCTION}

In September 2019 the German research icebreaker R/V Polarstern, was fixed to an ice floe north of the Laptev Sea with an aim to drift with the sea ice for a full year and eventually towards the Fram Strait [1]. As of now, the international Multidisciplinary drifting Observatory for the Study of Arctic Climate (MOSAiC) expedition is one of the largest Arctic expeditions in terms of the comprehensive in-situ measurements program. In order to improve the climate models and estimate essential climate change variables accurately, one of the major goal was to improve satellite based sea ice properties retrieval algorithms with the help of comprehensive year-around in-situ and air-borne measurements. In order to achieve this goal, comprehensive satellite-borne multi-frequency SAR acquisitions over the MOSAiC drift trajectory was put together by the Remote Sensing team. Thousands of SAR images were acquired in different imaging modes and frequencies supported by various international space agencies and research organizations (e.g. CSA, JAXA, ESA, DLR, KARI, ASI, CONAE, INTA). For more information about the MOSAiC expedition the reader is referred to https://www.mosaic-expedition.org.

During the campaign were a large dataset of spatially and temporally overlapping C- (RADARSAT-2) and L-band (ALOS-2 PALSAR-2) SAR images acquired. Previous studies e.g., [2, 3, 4, 5, 6, 7] have shown that L-band SAR can provide better separability between different sea ice types in 
specific scenarios and two frequencies can provide complementary information. Here we will compare the backscatter evolution for three different sea ice types; young ice (YI), smooth Ice (SI) and Rough/Deformed Ice (RDI). The different wavelengths means different penetration depths and different sensitives to the onset of melting e.g. [2], where L-band SAR provide easier separation between first year ice (FYI) and second/multi-year ice (SMYI) in the early and advanced melt season [6] and during dry ice winter conditions [4]. MYI is generally thicker, harder and with larger snow thickness than FYI and a successful classification between the two is therefore beneficial in both operational and scientific context. Based on the previous studies, we conclude that polarimetric L-band SAR provides a significant amount of robust information for sea ice characterization within the operational environment and also beneficial for scientific exploitation. Furthermore, future L-band missions such as ROSE-L or NISAR will offer the advantages of fully polarimetric acquisitions along with higher ground coverage to achieve a optimal scenario for L-band SAR based sea ice monitoring.

During MOSAiC the temperatures ranged from $-39.1{ }^{\circ} \mathrm{C}$ to $+6.8^{\circ} \mathrm{C}$ and it is therefore possible to study the effect of seasonality on the differences between C- and L-band SAR. From this we investigate stability of radar backscatter in different polarization, polarimetric parameters for different environmental conditions and at different incidence angles for a comprehensive C- and L-band SAR based sea ice type retrieval.

\section{DATASET}

R/V Polarstern was tided up to and drifted with two different ice floes during the MOSAiC expedition (Fig 1 ) The drift with the first floe started on 1 October 2019 until 31 July 2020 , and started at $85.1^{\circ} \mathrm{N} 133.6^{\circ} \mathrm{W}$ and ended at $79.0^{\circ} \mathrm{N}$ $2.5^{\circ} \mathrm{W}$. After a short interruption, the second MOSAiC floe started drifting on 21 August 2020 (from $87.8^{\circ} \mathrm{N} 104.4^{\circ} \mathrm{E}$ ) and the year-around expedition ended on 20 September 2020 at $89.0^{\circ} \mathrm{N} 109.8^{\circ} \mathrm{E}$. The first floe had two distinctly different parts, one consisted of deformed second year ice and the other part of smooth second year ice with a high $(>50 \%)$ fraction of refrozen melt ponds. The refrozen melt ponds were to a large part melted through in the previous summer and thus might have similar properties to First year SI. The sea ice observed in the larger area around R/V Polarstern for the first floe is the main focus of this study, where 100s of overlapping ALOS-2 PALSAR-2 images were acquired in different modes along with 250 fully-polarimetric RADARSAT- 2 images. R/V Polarstern drifted towards the polar hole (ca. above $86.6^{\circ} \mathrm{N}$ ) around the end of 2019 and the beginning of 2020 , there is therefore a gap in the RADARSAT- 2 and ALOS-2 PALSAR-2 fully-polarimetric images from January until midMarch and April respectively.

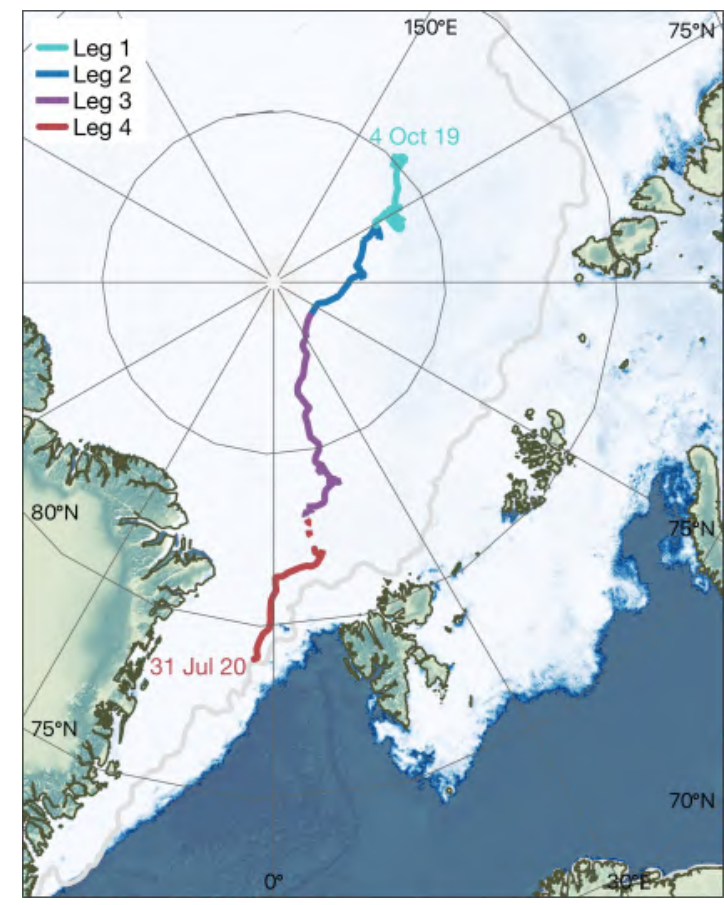

Fig. 1: Drift trajectory for the MOSAiC floe 1. The dashed line marks the time when R/V Polarstern had to leave the floe. The background shows sea ice concentration from AMSR2 (ASI $89 \mathrm{GHz}$, University of Bremen) on 3 March 2020, the maximum ice extent during the drift. The grey line marks the ice extent on 31 July 2020 at the end of floe 1 .

\section{METHODOLOGY}

The SAR images were both analysed for seasonal changes in backscatter intensity values for the three different sea ice types as well as classified using a well-established artificial neural network (ANN), e.g., [5], that has previously been used for sea ice classification using both frequencies.

For both analysis images were radiometrically calibrated using the included meta-data information for the respective satellite sensors and a $5 \times 5$-pixel median filter is applied to the data in order to reduce the noise effect before extraction of the polarimetric features. For the seasonal changes the images were incidence angle corrected to $35^{\circ}$ using the method and slope values outlined in [8], and the three different sea ice types were identified using manually drawn regions of interests (ROIs). For the ANN no incidence angle correction was applied to the images though the images were classified into the same three ice types as well as open water areas. For further information about the algorithm see, e.g., [5]. As an initial study we generated the training dataset for different ice types with the help of in-situ visual observation. It is important to note here that Smooth Ice (SI) class also contains smooth ice floes which might have survived one melting season. 

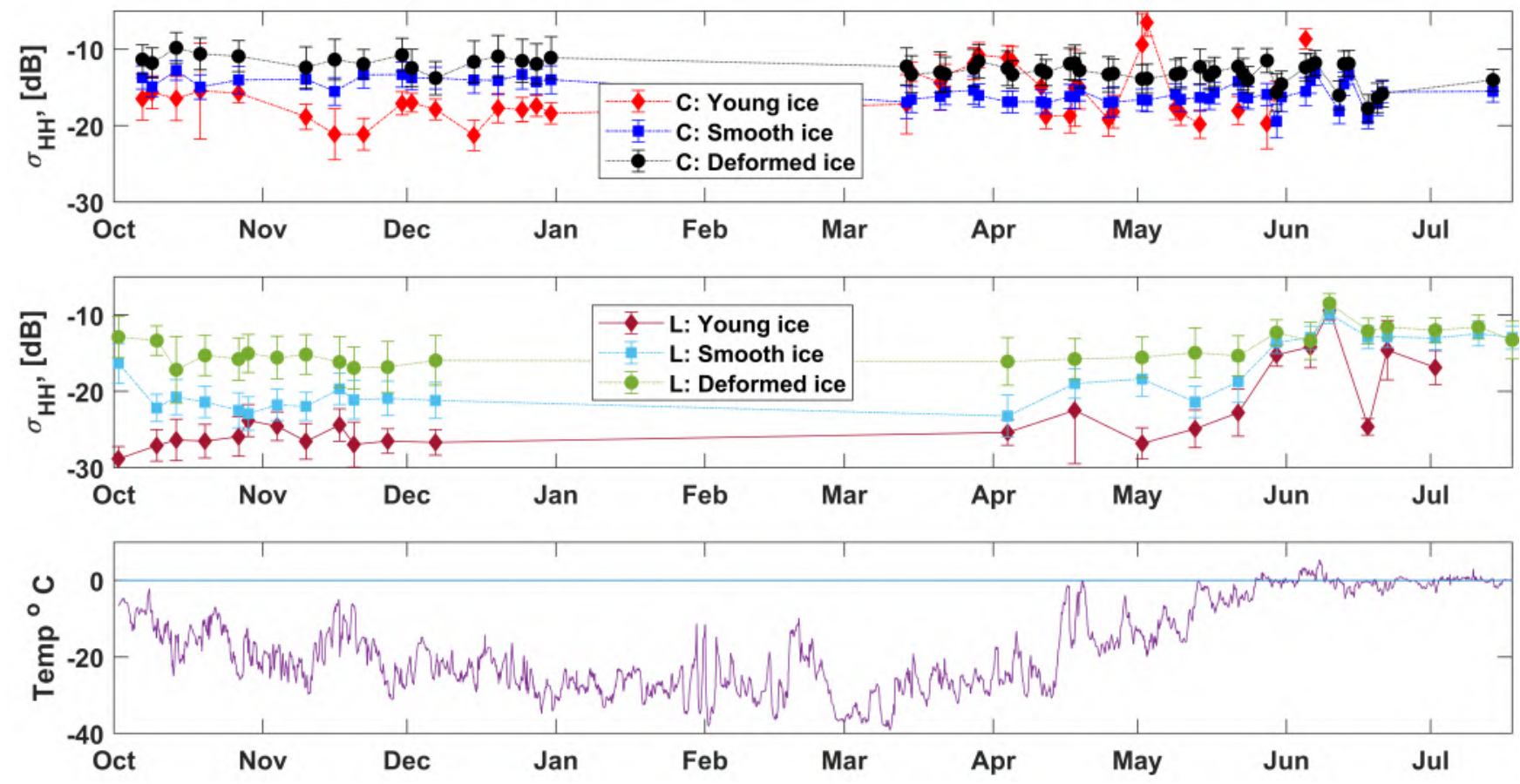

Fig. 2: The backscatter evolution for the HH-channel is shown for (top) RADARSAT-2 and (middle) ALOS-2. In (bottom) the temperature measured onboard R/V Polarstern is shown.
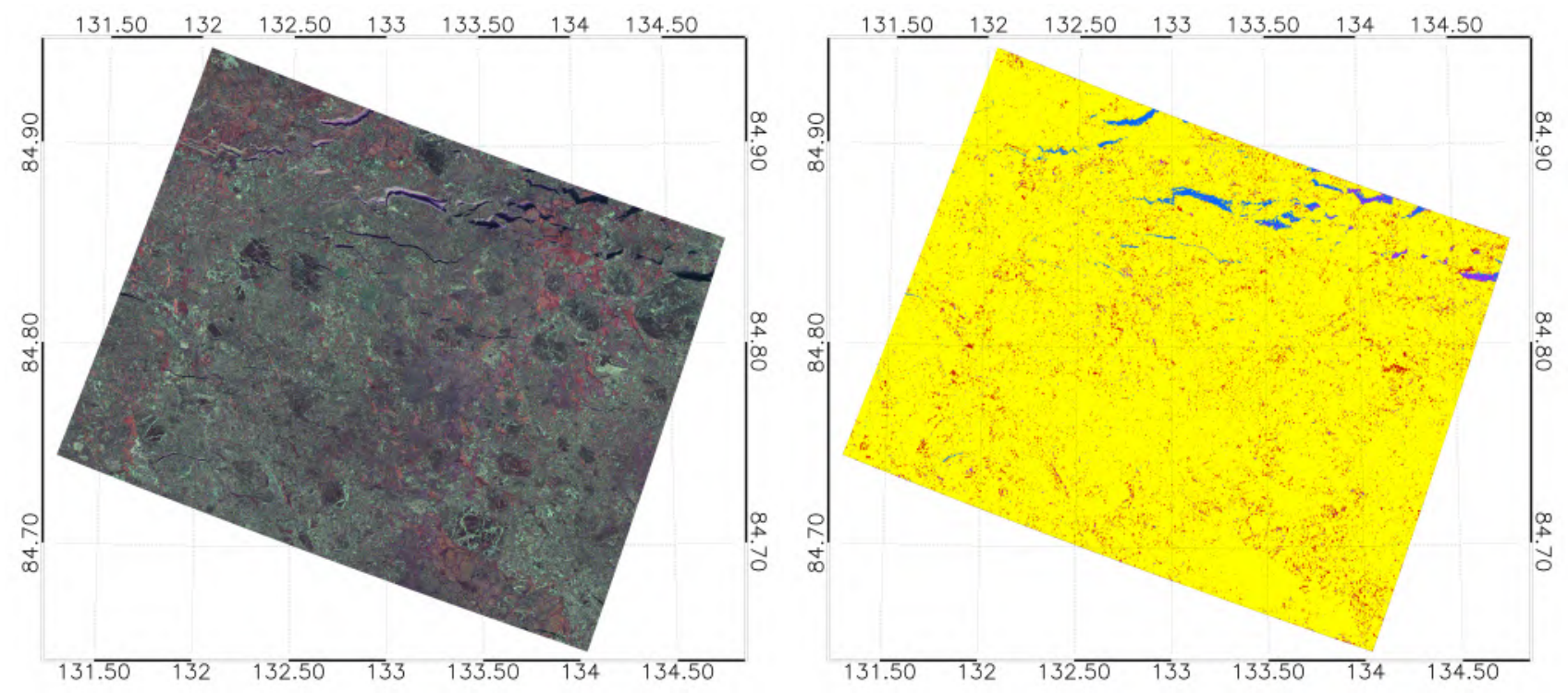

Fig. 3: RADARSAT-2 Fine QuadPol acquisition from the 19 October 2019 0404UTC. The incidence angle for this image is $29^{\circ}$ Left: Geocoded Pauli RGB composite (Red: HH-VV Green: HV+VH Blue: HH+VV)). Right: Corresponding classified scene where Open Water (OW) is blue, Young Ice (YI) purple, Smooth Ice (SI) yellow and Deformed Ice (DI) is red. 


\section{RESULTS AND DISCUSSION}

In Figure 2 the seasonal evolution of the backscatter values in $\mathrm{C}$ - and L-band are shown for the three different sea ice types. Similar to recent work by [6, 7] we observe larger differences between YI and DI backscatter values in the L-band data $(9-10 \mathrm{~dB})$ compared to the C-band data $(5-6 \mathrm{~dB})$. Moreover, the separation between the SI and the DI is larger in L-band compared to C-band regardless of season. A seasonal difference is observed for the co-polarization channels, where the difference is larger in L-band compared to C-band during the freezing season, comparable to those observations found by [4] during dry winter conditions. The standard deviation is significantly smaller for the SI compared to the DI in the L-band data, and moreover were the variability within the Lband data smaller than the C-band data. Toyota et al. [7] show that thin level ice can be better separated from deformed thin (pancake) and thicker FYI in L-band data compared to C-band data, here we argue that L-band could also be more suitable to reliable separate DI from SI.

There is noticeable higher backscatter values for the Lband data in early melt season (May, June) compared to the freezing season for all polarimetric channels. No such strong trend is found in the C-band RADARSAT-2 dataset. There is a slightly earlier seasonal change in the C-band data intensity values compared to the L-band data, probably caused by their different penetration depth and volume scattering sensitivities. Our results confirm earlier studies, e.g., [3, 4, 5, 7], that the $\mathrm{C}$ - and L-band data are complementary to one another and that through their slightly different dependencies on season and sea ice types, a combination of the two frequencies can aid improved sea ice classification. The availability of the high spatial and temporal resolution MOSAiC dataset combined with in-situ information ensures that seasonal changes can be fully explored.

In Figure 3 a RADARSAT-2 Fine QuadPol image is shown together with the classified image. Part of MOSAiC ice floe along with $\mathrm{R} / \mathrm{V}$ Polarstern is present at far range of the swath. Smoother portion of the MOSAiC ice floe which is actually contain refrozen melt pond is classified as SI. Leads and refrozen leads (here treated as YI) in the vicinity of the MOSAiC floe is also correctly identified, although in some cases very thin refrozen leads classified as open water. To some degree the Deformed Ice is underrepresented in Figure 3. Currently we are analyzing an extensive amount of in-situ and airborne measurements to prepare a representative training dataset and results will be reported in future studies.

\section{CONCLUSIONS}

During the course of MOSAiC, a comprehensive set of L- and C-band SAR images were acquired. In this preliminary paper we presented incidence angle normalized seasonal evaluation of L- and C-band backscatter and highlighted their behavior during the winter and melt-onset season. We also carried out preliminary sea ice type classification withing the vicinity of the MOSAiC ice floe with three major ice types and open water. We are currently working on incorporating various insitu measurements to fine tune the sea ice type classification algorithm and validation.

\section{REFERENCES}

[1] T. Krumpen and et. al., "The MOSAiC ice floe: sedimentladen survivor from the siberian shelf," The Cryosphere, vol. 14, no. 7, pp. 2173-2187, 2020.

[2] J. A. Casey, S. E. Howell, A. Tivy, and C. Haas, "Separability of sea ice types from wide swath $\mathrm{C}$ - and L-band synthetic aperture radar imagery acquired during the melt season," Remote Sensing of Environment, vol. 174, pp. $314-328,2016$.

[3] A. M. Johansson, C. Brekke, G. Spreen, and J. A. King, "X-, C-, and L-band SAR signatures of newly formed sea ice in Arctic leads during winter and spring," Remote Sensing of Environment, vol. 204, no. Supplement C, pp. $162-180,2018$.

[4] M. Dabboor, B. Montpetit, S. Howell, and C. Haas, "Improving sea ice Characterization in Dry Ice Winter Conditions Using Polarimetric Parameters from C- and L-Band SAR Data," Remote Sensing, vol. 9, no. 1270, 2017.

[5] S. Singha, A. M. Johansson, N. Hughes, S. Munk Hvidegaard, and H. Skourup, "Arctic Sea Ice Characterization using Spaceborne Fully Polarimetric L-, C- and X-band SAR with Validation by Airborne Measurements," IEEE T. Geoscience and Remote Sensing, vol. 56, no. 7, pp. 3715-3734, 2018.

[6] M. S. Mahmud, V. Nandan, S. E. Howell, T. Geldsetzer, and J. Yackel, "Seasonal evolution of 1-band sar backscatter over landfast arctic sea ice," Remote Sensing of Environment, vol. 251, p. 112049, 2020.

[7] T. Toyota, J. Ishiyama, and N. Kimura, "Measuring deformed sea ice in seasonal ice zones using 1-band sar images," IEEE Transactions on Geoscience and Remote Sensing, pp. 1-21, 2020.

[8] M. S. Mahmud, T. Geldsetzer, S. E. L. Howell, J. J. Yackel, V. Nandan, and R. K. Scharien, "Incidence Angle Dependence of HH-Polarized C- and L-Band Wintertime Backscatter over Arctic Sea Ice," IEEE Trans. Geosci. Remote Sens, 2018. 